\title{
Modeling the impact of inclusion of family planning services in Ghana's National Health Insurance scheme
}

\author{
Justin Archer \\ Gillian Eva \\ Augustine Ankomah \\ Population Council \\ Saumya RamaRao \\ Population Council \\ Kamil Fuseini \\ Population Council
}

See next page for additional authors

Follow this and additional works at: https://knowledgecommons.popcouncil.org/departments_sbsr-rh

Part of the Health Policy Commons, and the Health Services Research Commons

How does access to this work benefit you? Let us know!

\section{Recommended Citation}

Archer, Justin, Gillian Eva, Augustine Ankomah, Saumya RamaRao, Kamil Fuseini, Anne Coolen, Stephen Duku, and Benjamin Bellows. 2020. "Modeling the impact of inclusion of family planning services in Ghana's National Health Insurance scheme." New York: Population Council. 


\section{Authors}

Justin Archer, Gillian Eva, Augustine Ankomah, Saumya RamaRao, Kamil Fuseini, Anne Coolen, Stephen Duku, and Benjamin Bellows 


\section{MODELING THE IMPACT OF INCLUSION OF} FAMILY PLANNING SERVICES IN GHANA'S NATIONAL HEALTH INSURANCE SCHEME

Justin Archer, Gillian Eva, Augustine Ankomah, Saumya RamaRao, Kamil Fuseini, Anne Coolen, Stephen Duku, and Ben Bellows 



\section{Population COUNCIL \\ Ideas. Evidence. Impact.}

The Population Council confronts critical health and development issues - from stopping the spread of HIV to improving reproductive health and ensuring that young people lead full and productive lives. Through biomedical, social science, and public health research in 50 countries, we work with our partners to deliver solutions that lead to more effective policies, programs, and technologies that improve lives around the world. Established in 1952 and headquartered in New York, the Council is a nongovernmental, nonprofit organization governed by an international board of trustees.

Population Council

One Dag Hammarskjold Plaza

New York, New York 10017

USA

Tel: +12123390500

Fax: +1 6462778243

email: pubinfo@popcouncil.org

popcouncil.org

Suggested citation: Archer, J., Eva, G., Ankomah, A., RamaRao S., Fuseini, K., Coolen, A., Duku, S., and Bellows, B. 2020. "Modeling the impact of inclusion of family planning services in Ghana's National Health Insurance Scheme.” New York, New York: Population Council. 



\section{Table of Contents}

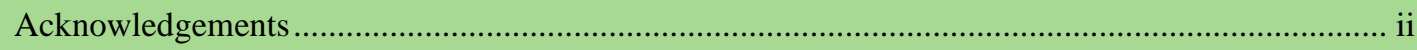

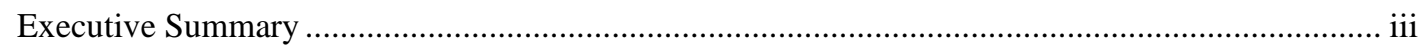

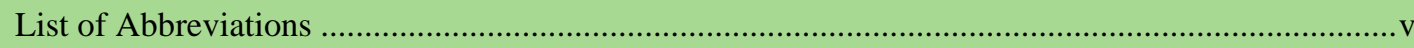

Introduction

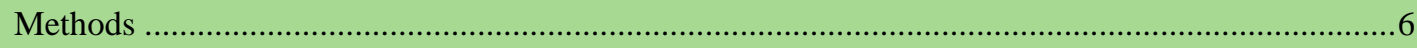

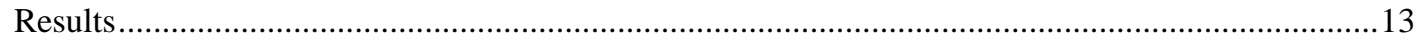

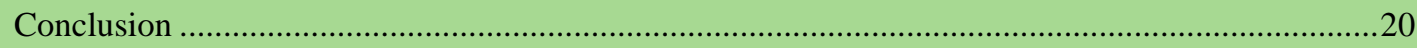

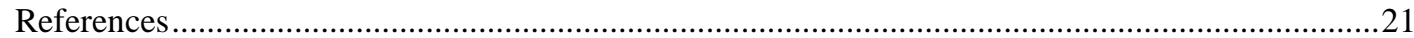

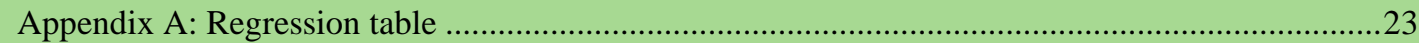

Appendix B: Review of 2015 report How Ghana Can Save Lives and Money: The Benefits of Financing Family Planning through National Health Insurance ......................................................24

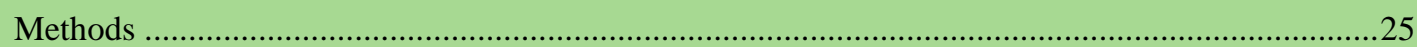

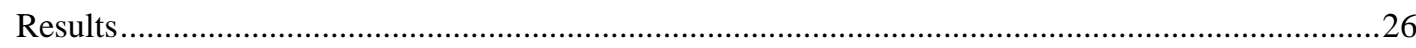

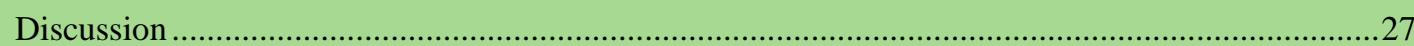




\section{Acknowledgements}

We thank the National Health Insurance Authority, Ghana Health Service, Luke Boddam-Whetham at Marie Stopes International, Michael Chaitkin at George Washington University- Milken Institute School of Public Health, Ellen Smith, Jay Gribble and Kaja Jurcynska at The Palladium Group, and Leah Jarvis and Michelle Hindin at Population Council.

The Population Council received a grant to conduct the evaluation of the inclusion of FP within the National Health Insurance Benefits Package in Ghana from the Bill \& Melinda Gates Foundation. However the views expressed do not necessarily reflect the official policies of the Foundation. 


\section{Executive Summary}

While access to and uptake of modern family planning (FP) in Ghana has steadily risen over the last decade, the modern Contraceptive Prevalence Rate (mCPR) among all women reached only 22\% in 2019 with $30 \%$ of women still reporting an unmet need.

In an effort directed at increasing FP uptake via mitigation of cost barriers among women with an unmet need, the Government of Ghana is seeking to integrate claims-based FP services into the National Health Insurance Scheme (NHIS) benefits package. The impact of this initiative has the potential to be significant with the proportion of women accessing modern FP shifting dramatically to public facilities over the past decade, driven in part by a change in preferences to long-acting contraceptive methods that can only be provided by certain cadres of health providers, most of whom work in the public sector.

About one third of recent or current users of FP services reported receiving services for free, while less than two percent name 'cost' as the main reason for not using FP or the main reason for discontinuing a method. Addressing only cost as a barrier may therefore have limited effectiveness but the possibility of 'cost' falling second or third in the priority list of non-use reasons inspires investigation. Additional policies and activities running concurrently may also increase the impact of removing cost barriers beyond their own impacts on FP uptake.

Resultantly, the Ghana Ministry of Health, the National Health Insurance Authority (NHIA), Marie Stopes International Ghana (MSI Ghana), and the Population Council launched a pilot in nine districts from May 2018 to April 2020. Claims-reimbursable FP services were implemented in seven districts, FP demand generation activities in two districts, and provider training in insertion and removal of long-acting reversible contraceptives (LARCs) in three districts.

This report uses data from the pilot activity to model four scenarios involving the implementation of cost removal, demand generation, and LARC training to estimate the impacts of these activities on mCPR. These are then inputted into the Health Policy Project's ImpactNow tool to obtain estimates of health and economic benefits, intended for use by the Government of Ghana and policymakers to inform their decisions regarding the scale-up of these activities across the country. The scenarios and modeled mCPR increases are as follows:

1. Non-intervention scenario: This scenario assumes that no additional FP interventions are undertaken and the mCPR trend seen over the last 10 years (2008-2019) continues. This results in an annual mCPR increase of $0.8 \%$ and a final mCPR in 2025 of $26.2 \%$.

2. Cost reimbursement only scenario: This scenario adds the expected effect on mCPR of removing the cost of FP services onto our non-intervention scenario. This results in an annual $\mathrm{mCPR}$ increase of $1.6 \%$ and a final $\mathrm{mCPR}$ in 2025 of $30.4 \%$. The calculation for this is described later in this report.

3. Multiple intervention scenario: This scenario takes into account the baseline trend in mCPR and the interaction effect of the complementary activities aimed at fully capitalizing on the NHIS: removing cost of FP services, training of providers in LARC services, and increased demand generation activities. This results in an annual mCPR increase of $2.8 \%$ and a final mCPR in 2025 of $36.2 \%$. The calculation for this is described later in this report.

4. Maximum mCPR scenario: This scenario is based on projections conducted by Avenir Health showing the maximum possible mCPR in Ghana, assuming demand (as measured by fertility

iii | Research Report 
intentions) remains the same (Avenir Health, 2018). This results in an annual mCPR increase of $4.6 \%$ and a final mCPR (note this is for married not all women) in 2025 of $45 \%$.

In all scenarios, health outcomes are positive. From 2021 through 2025, the cost reimbursement program alone would result in an estimated 5,000 infant and maternal lives saved and 369,900 unintended pregnancies averted. Expanding the initiative to include demand generation activities and LARC training across the country would increase the number of infant and maternal lives saved and unintended pregnancies averted by an additional twenty-five percent.

The economic impacts of these scenarios are also highly beneficial from 2021 through 2025. FP service cost reimbursement would save \$30.1 million (GHS 174.7 million) in healthcare costs in that span, which is greater than the estimated \$7.5 million (GHS 43.4 million) in additional costs to reimburse for FP services. This 4.03 benefit-cost ratio shows that the cost savings of implementing these initiatives would outweigh the costs of the initiatives themselves. The inclusion of demand generation activities and LARC training would add a cumulative $\$ 12.9$ million (GHS 74.8 million) in total FP costs but would avert $\$ 30.1$ million (GHS 174.7 million) in other healthcare costs.

Avenir Health's estimation for the maximum possible mCPR in Ghana is $45 \%$ by 2025 . Implementing FP service cost reimbursement would advance mCPR from our baseline projection of $26.2 \%$ to $30.4 \%$ in 2025, making up one-fifth of this gap. The addition of demand generation activities and LARC training advances mCPR to an estimated $36.2 \%$, just over half of that gap. These programs will bring access to FP to women covered by the NHIS, and efforts to expand coverage would only further diminish the unmet need gap.

The results from this analysis show that while removal of financial barriers to FP will have a potentially small positive effect on FP uptake, mCPR, and long-term health outcomes, a much greater impact will be seen if additional interventions are also implemented. Inclusion of FP in the NHIS benefits package focuses only on the financial barriers to FP access, while LARC training and demand generation address additional barriers such as availability of and awareness of FP. It is crucial that interventions reach women who are not currently using FP since it is only by reaching those women that any impact on mCPR will be seen. 


\section{List of Abbreviations}

\begin{tabular}{ll} 
CHPS & Community-based Health Planning Services \\
\hline CPR & Contraceptive Prevalence Rate \\
\hline DALY & Disability-Adjusted Life Year \\
\hline DHIMS & District Health Information and Management System \\
\hline FP & Family Planning \\
\hline GDHS & Ghana Demographic and Health Survey \\
\hline GHS & Ghana Health Service \\
\hline GMHS & Ghana Maternal Health Survey \\
\hline IUD & Intra-Uterine Device \\
\hline LAM & Lactational Amenorrhea Method \\
\hline LAPM & Long-Acting or Permanent Method \\
\hline LARC & Long-Acting Reversible Contraception \\
\hline mCPR & Modern Contraceptive Prevalence Rate \\
\hline MICS & Multiple Indicator Cluster Survey \\
\hline MSI & Marie Stopes International \\
\hline MSI Ghana & Marie Stopes International Ghana \\
\hline MMR & Maternal Mortality Rate \\
\hline NHIA & National Health Insurance Authority \\
\hline NHIS & National Health Insurance Scheme \\
\hline TFR & Performance Monitoring \& Accountability \\
\hline
\end{tabular}





\section{Introduction}

The Government of Ghana is piloting the integration of family planning (FP) into the National Health Insurance Scheme (NHIS) benefits package in credentialled health facilities in nine districts in Ghana. It is anticipated that this will lead to an increase in access to and uptake of modern FP methods. This report describes a modeling exercise conducted to estimate the wider health impact of an increase in uptake of modern FP methods due to inclusion in the NHIS benefit package, resulting from the shift in method mix and increase in modern Contraceptive Prevalence Rate (mCPR) among all women of reproductive age in Ghana. We estimate the direct effect on access and uptake of 1) removing the outof-pocket cost barrier to FP through inclusion in the NHIS package and 2) addressing other barriers to uptake as part of a wider FP strategy accompanying the NHIS benefits expansion. We use data from a pilot conducted by the Ghana Ministry of Health, Ghana Health Service, the National Health Insurance Authority (NHIA), Marie Stopes International Ghana (MSI Ghana), and the Population Council to estimate the effect of FP interventions on uptake. We also use the ImpactNow tool ${ }^{1}$ to estimate the wider health and cost impact of increased uptake.

\section{The context of FP and maternal health in Ghana}

While mCPR remains low and unmet need remains high, the FP landscape in Ghana has changed substantially in the last decade in terms of a steady increase in access to and uptake of modern FP (TABLE 1). MCPR among all women of reproductive age (aged

TABLE 1. Modern CPR trends

\begin{tabular}{lcc}
\hline Modern CPR & & \\
\hline Year & $\begin{array}{c}\text { All women } \\
\text { (aged 15-49) }(\%)\end{array}$ & $\begin{array}{c}\text { Married/cohabiting women } \\
\text { (aged 15-49) (\%) }\end{array}$ \\
\hline 2019 (projection) $^{1}$ & 22.2 & 28.5 \\
$2017^{2}$ & 19.5 & 25.0 \\
$2014^{3}$ & 18.2 & 22.2 \\
$2011^{4}$ & N/A & 23.4 \\
$2005^{5}$ & 13.5 & 16.6 \\
Sources: ${ }^{1 T r a c k 20 ; ~} 2017$ GMHS; 32014 GDHS; 4.2011 MICS; 52008 GDHS
\end{tabular}
(Ghana Statistical Service et al., 2009) and projections suggest an ongoing upward trend (Track20, 2020). Among married women aged 15-49 years, mCPR increased from 23.4\% in 2011 (Ghana Statistical Service, 2011) to 25.0\% in 2017 (Ghana Statistical Service (GSS) et al., 2018). Thirty percent of women had an unmet need for FP in 2014, compared to 35.3\% in 2008 (Ghana Statistical Service et al., 2009; Ghana Statistical Service (GSS) et al., 2015) (data not shown). Method mix has remained mostly unchanged in the last decade, with a few notable exceptions: among all women aged 15-49 the percentage using implants increased from $0.7 \%$ in 2008 to $5.3 \%$ in 2017 and the percentage using injectables increased from $4.2 \%$ to $6.0 \%$ over the same period (Ghana Statistical Service et al., 2009; Ghana Statistical Service (GSS) et al., 2018). TABLE 2 shows the method mix change from 2008 to 2017 among women using FP. Similarly, total fertility rate (TFR) remains essentially unchanged at 3.9 in 2017 compared to 4.0 in 2008 (Ghana Statistical Service et al., 2009; Ghana

1 ImpactNow is an Excel-based model updated by Health Policy Plus from Marie Stopes International's Impact 2 tool. 
Statistical Service (GSS) et al., 2018). In contrast, the maternal mortality ratio in Ghana has dropped from 484 maternal deaths per 100,000 live births in 2000 to 308 in 2017 (WHO et al., 2019).

TABLE 2. Method mix trends

\begin{tabular}{|c|c|c|c|c|c|c|c|c|}
\hline Year & $\begin{array}{c}\text { Female } \\
\text { Sterilization } \\
(\%)\end{array}$ & $\begin{array}{l}\text { IUD } \\
(\%)\end{array}$ & $\begin{array}{c}\text { Implants } \\
(\%)\end{array}$ & $\begin{array}{c}\text { Injectables } \\
(\%)\end{array}$ & $\begin{array}{l}\text { Pill } \\
(\%)\end{array}$ & $\begin{array}{l}\text { Male } \\
\text { Condoms } \\
(\%)\end{array}$ & $\begin{array}{l}\text { Other modern } \\
\text { method } \\
(\%)\end{array}$ & $\begin{array}{l}\text { Traditional } \\
\text { methods } \\
(\%)\end{array}$ \\
\hline $2017^{1}$ & 4.9 & 2.0 & 21.5 & 24.3 & 13.4 & 6.5 & 6.1 & 21.5 \\
\hline $2014^{2}$ & 5.8 & 2.2 & 16.4 & 26.7 & 17.3 & 8.9 & 2.2 & 20.4 \\
\hline $2008^{3}$ & 5.2 & 1.0 & 3.6 & 21.8 & 18.7 & 18.7 & 1.0 & 30.4 \\
\hline \multicolumn{9}{|c|}{$\begin{array}{l}\text { Notes: 'Other modern methods' include: male sterilization; female condoms; diaphragm; foam/jelly; emergency contraception and LAM. } \\
\text { 'Traditional methods' include: rhythm; withdrawal, folk method, and 'other'. The following methods were reported as being used by } 0 \% \\
\text { of respondents: male sterilization, female condom, diaphragm, foam/jelly. }\end{array}$} \\
\hline
\end{tabular}

To consider the role that the NHIS could play in improving access to modern FP methods, we need to understand from where women are currently getting their methods, whether or not they pay, whether or not cost is a barrier to them accessing FP, and whether or not they are covered by the NHIS. Data presented in TABLE 3 shows that most women who are using modern FP got their method at a public facility, and that proportion has grown dramatically over the last decade, from $39.4 \%$ in 2008 to $63.7 \%$ in 2014 (Ghana Statistical Service et al., 2009; Ghana Statistical Service (GSS) et al., 2015). This is likely due to the shift from short-acting methods or over-the-counter methods to longacting and permanent methods, which can only be provided by certain cadre of health professionals, most of whom work in the public sector, and the increased focus on Community-based Health Planning Services (CHPS) which make FP accessible and affordable through the public sector in rural areas (Aviisah et al., 2018). The majority of methods delivered through the private sector are pills and condoms, whereas the majority of services delivered at public facilities are intrauterine devices (IUDs), injectables, implants, and female sterilization (data not shown). This shows a clear divide between short- and long-acting methods by source of FP and also suggests that the vast majority of women choosing a long-acting or permanent method of FP get their service from the public sector.

About one third of recent or current users of FP services reported receiving services for free (Performance Monitoring and Accountability 2020 (PMA2020) Project et al., 2013), while less than $2 \%$ name 'cost' as the main reason for not using FP or the main reason for discontinuing a method (Ghana Statistical Service et al., 2009; Ghana Statistical Service (GSS) et al., 2015) (note that the wording for this question differed by year see - notes in TABLE 3). According to data from the latest Ghana Maternal Health Survey (GMHS) and Ghana Demographic and Health Survey (GDHS), in 2017 almost $80 \%$ of women were registered with the NHIS, almost unchanged since 2014. However, the proportion of women who had coverage through the NHIS dropped substantially from $62.0 \%$ (2014) to 45.9\% (2017), reflecting a drop in new enrollments since 2015 and a drop in renewals since 2013 possibly caused by long waiting times to register, certain services not being included, and perceived poor quality of services for NHIS clients (Nsiah-Boateng \& Aikins, 2018). This disparity between the number of registered and the number covered is explained by women who are not up to date with payments or are in the waiting period. 


\section{The role of Health Insurance in access to and uptake of family planning}

In the context of the Millennium and Sustainable Development Goals, many countries have incorporated health financing schemes into their efforts to achieve Universal Health Coverage, with the ultimate goal of making health services available to everyone without undue financial burden. However, reproductive health was often not included in these efforts. This is of particular concern as the future availability of donor funds for sexual and reproductive health programs become less certain, affecting the reach and sustainability of national service delivery. In the context of FP2020, and as governments of low- and middle-income countries are being expected to take on more of the costs of reproductive healthcare domestically, some countries have begun expanding their health financing schemes to include maternal health, reproductive health and, to a lesser degree, FP. One way this has been done is by including these services as benefits in National Health Insurance programs. However, best practice guidance or examples of how this should be done have not yet been established (Eldridge \& Staples, 2018). It is not enough just to include FP services in Universal Health Coverage schemes, the details of how FP is included in National Health Insurance is crucial, including focusing on the people reached, the package of services, the providers, and how and for what payments are made (Mazzilli et al., 2016). 
TABLE 3. Cost and FP in Ghana

\begin{tabular}{|c|c|c|}
\hline \multicolumn{3}{|c|}{ Modern CPR } \\
\hline Year & Public (\%) & Private (\%) \\
\hline $2014^{1}$ & 63.7 & 33.4 \\
\hline $2008^{2}$ & 39.4 & 51.1 \\
\hline \multicolumn{3}{|c|}{ Modern FP users who received services for free* } \\
\hline Year & \multicolumn{2}{|c|}{$\%$ who received FP for free } \\
\hline 20173 & \multicolumn{2}{|r|}{36.2} \\
\hline $2016^{3}$ & \multicolumn{2}{|r|}{32.4} \\
\hline $2015^{3}$ & \multicolumn{2}{|r|}{24.9} \\
\hline 20143 & \multicolumn{2}{|r|}{29.9} \\
\hline $2008^{2}$ & \multicolumn{2}{|r|}{3.4} \\
\hline \multicolumn{3}{|c|}{ Cost as a reason for not using FP** } \\
\hline Year & \multicolumn{2}{|c|}{$\%$ for whom cost is the reason for not using } \\
\hline $2014^{1}$ & \multicolumn{2}{|r|}{1.2} \\
\hline $2008^{2}$ & \multicolumn{2}{|r|}{0.7} \\
\hline \multicolumn{3}{|c|}{ Health Insurance registration and coverage } \\
\hline Year & NHIS coverage (women 15-49) (\%) & Registered with insurance (women 15-49) (\%) \\
\hline $2017^{4}$ & 45.9 & 79.4 \\
\hline $2014^{1}$ & 62.0 & - \\
\hline $2008^{2}$ & 38.8 & - \\
\hline
\end{tabular}

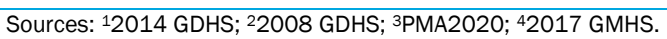

Notes:
This question had a low response rate.
Question wording differs by source and year: GDHS question: Percentage of current users of modern contraceptive
methods age 15-49 who received their last FP method free. PMA2020 question: \% of married modern contraceptive
users who paid for FP services in the past 12 months (data presented is reversed to match GDHS question)
Question wording differs by year. GDHS 2008 question: Percent distribution of currently married women who are not
using a contraceptive method and who do not intend to use a method in the future by main reason for not intending to
use contraception, according to age, Ghana 2008. GDHS 2014 question: Percent distribution of discontinuations of
contraceptive methods in the five years preceding the survey by main reason stated for discontinuation, according to
specific method, Ghana 2014 .
For 2014 , data presented is the proportion who discontinued modern methods (implant, pills, injectables). IUD is
included in 'other'. Note that this will underestimate the proportion of women for whom cost is a barrier because it
excludes those who have never used FP. In addition, a sizeable proportion of women who have never used might be
adolescents, for whom cost might be a bigger barrier than for women over 25.
Question wording differs by year. GDHS 2014 question: are you registered with NHIS? MHS 2017 question: are you
registered with any insurance?
Non-NHIS insurance is extremely uncommon (1.3\% in 2008; $0.7 \%$ in 2014; $0.3 \%$ in 2017).
Registered includes those who have coverage

Ghana's National Health Insurance Scheme

Ghana's NHI Act was passed in 2003 (Act 650), amended in 2008 (Act 753) and revised in 2012 (Act 852). The NHI Act indicates that free ante-natal, delivery and neo-natal healthcare services be provided by the Scheme. Since then the country has seen a drop in maternal mortality rate (MMR) from 371 maternal deaths per 100,000 live births in 2005 to 308 in 2017 (WHO et al., 2019). In 2012, the revised NHI Act (Act 852) prescribed the addition of FP into the NHIS benefits package, but this has yet to be implemented in part because of a lack of understanding of how this should be done, as noted above. 
At the same time, the Government of Ghana currently has an ambitious and proactive approach to increasing access to and uptake of FP, evidenced by their 2012 FP2020 pledges, the 2016-2020 Ghana FP Costed Implementation plan, and their updated 2017 FP2020 commitment (FP2020, 2017; Government of Ghana., 2015). A key priority through all these documents remains to eliminate FP user fees by including FP in the suite of NHIS benefits. In an effort to move from policy to practice, the Ministry of Health, National Health Insurance Authority, and the Ghana Health Service partnered with MSI Ghana and The Population Council to pilot the inclusion of FP services in the NHIS benefits package. The pilot, which began in May 2018, combined delivery of all modern clinical FP methods for free to insured clients at all NHIS-accredited public and private facilities with awareness creation in seven districts. In addition to the removal of out-of-pocket cost program, community level demand generation activities were implemented in two districts. Further, the pilot included training of providers in long acting reversible contraceptives (LARCs) in three districts, which elevated the total number of districts receiving some combination of interventions to nine. Table 4 outlines the district assignment within these intervention arms. For full details of the pilot design and implementation (see Ankomah et al., 2020; Boddam-Whetham \& Duku, 2019).

TABLE 4. Pilot district and intervention assignment

\begin{tabular}{lccc}
\hline District & Claims Reimbursable & Demand Generation & LARC Training \\
\hline Bolgatanga & $\mathrm{X}$ & $\mathrm{X}$ & $\mathrm{X}$ \\
Municipal & $\mathrm{X}$ & & \\
Nabdam & $\mathrm{X}$ & & \\
Bawku West & $\mathrm{X}$ & $\mathrm{X}$ \\
Mfantsiman & $\mathrm{X}$ & & \\
Ekumfi & & \\
Upper Denkyira East & & $\mathrm{X}$ \\
Upper Denkyira & & \\
West & $\mathrm{X}$ & \\
Obuasi & $\mathrm{X}$ & \\
Adaklu & Note: Marked cells indicate whether each intervention was implemented within the district & \\
\hline
\end{tabular}




\section{Objectives}

The objectives of this modeling exercise were to:

- model how adding FP to the NHIS benefits package might affect health outcomes; and

- model how additional elements of the NHIS pilot (i.e., demand generation activities and provider training in LARCs) might affect health outcomes.

In order to estimate the health outcomes of increased FP uptake, we first needed to estimate how each intervention might affect national mCPR. 


\section{Methods}

In order to determine how different FP interventions might affect health outcomes, we first needed to estimate how each intervention might affect national mCPR. Due to uncertainty about the actual impact on $\mathrm{mCPR}$, and to account for the fact that the removal of financial barriers is just one part of a wider effort by the government of Ghana to increase access to FP, we developed four possible mCPR scenarios. These were: non-intervention as a lower bound; basic cost reimbursement of FP services; multiple intervention; and maximum attainable mCPR as an upper bound, replicating the general approach of a 2015 Ghana modeling exercise (Chaitkin et al., 2015) ${ }^{2}$. The scenarios were then used to estimate the impact of a range of potential concurrent interventions on $\mathrm{mCPR}$.

While the central goal of the NHIA is to remove the financial barriers to FP services, it can and should take a more holistic approach to making FP services more accessible in order to maximize its impact. As per a 2018 paper by Eldridge and Staples, while "financing mechanisms are best at addressing financing barriers; other non-financial barriers still exist for FP and will need to be addressed" (Eldridge \& Staples, 2018). These additional approaches informed our modeling of estimates for the impact of the NHIA's undertaking. For example, the credentialling of facilities by the NHIA gives the government the opportunity to ensure minimum quality standards at facilities, including building the capacity of providers to provide quality FP services and a full method mix, ensuring women have method choice. In addition, for health insurance schemes to maximize efficiency they should also promote 'wellness' and preventive healthcare seeking behavior among insurance clients. In this context, demand generation to encourage uptake of FP helps to avoid the more expensive potential healthcare needs arising from unintended pregnancies.

Based on this holistic approach to NHIS implementation, the following interventions were included in the modeling of the four mCPR scenarios, by which we mean we will estimate the impact on FP uptake of each of these interventions and how it will affect overall mCPR and method mix.

FP interventions included in $\mathrm{mCPR}$ scenarios

Supply

\section{Removing fees for FP services at public and private health facilities.}

Removing fees is a priority for the Government of Ghana (operationalizing FP inclusion in the NHIS) and is the key focus of the ongoing pilot. We estimated the impact of removing fees on FP uptake by looking at the number of new FP users and method mix before and after the removal of fees. To scale this up to national level mCPR change we took into account the proportion of the population with unmet need and the population size. We 'deflated' the expected impact on mCPR based on the proportion of women for whom cost is a barrier, and the proportion of women who have NHIS coverage. Finally, to account for differences between the pilot districts and the rest of Ghana, we took into account a number of key variables that had been found to influence FP uptake as covariates in our model. In a study of households in the Upper East Region of Ghana, it was found that use of contraceptives was significantly related to exposure to integrated primary healthcare services, the level of education, and socioeconomic status, couple fertility preference,

\footnotetext{
2 For a review of this report and a comparison of their scenarios to updated projections of mCPR changes see Appendix B.
} 
marital status, and parity (Achana et al., 2015). We considered as appropriate equivalents to these characteristics our available data on population, percent of population classified as rural, total fertility rate, and number and type of health facilities.

\section{Increasing Availability of LARCs.}

Providing access to the full range of contraceptives is a priority for the Government of Ghana and can be directly affected by the NHIS through training of providers at NHIS accredited facilities. Long-acting methods are more effective than short-acting methods and have a greater impact on mCPR due to their longer potential lifespan. By increasing the number of trained providers, as well as the range of methods that are being offered, we expect FP uptake overall to increase and specifically uptake of long-acting methods to increase. The impact of increased availability of LARCs was combined with the impact of demand-generation.

\section{Demand}

\section{Increasing demand-generation activities to encourage wellness and preventive healthcare seeking behavior, specifically uptake of FP.}

Demand generation activities are a crucial element of any FP program, especially to ensure that new users and hard to reach populations are reached, in addition to providing services to continuing FP users. The impact of demand generation activities was combined with the impact of increasing availability of LARCs through inclusion of both interventions with fee removal as an interaction term in the regression model.

\section{Modern CPR scenarios used for modeling}

Our analysis uses the ImpactNow tool, which uses changes in mCPR as inputs to calculate health and cost impacts of those changes. As such, we describe in this methods section how we arrived at our mCPR input figures. The mCPR increases are based on a 2019 baseline mCPR among all women of $22.2 \%$ and unmet need of $32.9 \%$ (Track20, 2020).

- Non-intervention scenario: This scenario assumes that no additional FP interventions are undertaken and the mCPR trend seen over the last 10 years (2008-2019) continues. This results in an annual mCPR increase of $0.8 \%$ and a final mCPR in 2025 of $26.2 \%$.

- Cost reimbursement only scenario: Basic cost reimbursement of FP services scenario. This scenario adds the expected effect on mCPR of removing the cost of FP services onto our nonintervention scenario. This results in an annual mCPR increase of $1.6 \%$ and a final $\mathrm{mCPR}$ in 2025 of $30.4 \%$. The calculation for this is described later in this report.

- Multiple intervention scenario: This scenario takes into account the baseline trend in mCPR and the interaction effect of the complementary activities aimed at fully capitalizing on the NHIS: removing cost of FP services, training of providers in LARC services, and increased demand generation activities. This results in an annual mCPR increase of $2.79 \%$ and a final $\mathrm{mCPR}$ in 2025 of $36.2 \%$. The calculation for this is described later in this report.

- Maximum mCPR scenario. This scenario is based on projections conducted by Avenir Health showing the maximum possible mCPR in Ghana, assuming demand (as measured by fertility intentions) remains the same (Track20, 2020). This results in an annual mCPR increase of $4.6 \%$ and a final mCPR (note this is for married not all women) in 2025 of $45 \%$. 
We also describe other current or planned interventions which may affect modern FP uptake but are not included in our analysis, either due to lack of detail on what the intervention entails, lack of clarity over when/whether the intervention would be initiated, or lack of quality data on the impact of the intervention on FP uptake.

Using ImpactNow, we modeled the societal and health impacts of the increased services for all four $\mathrm{mCPR}$ scenarios, as well as the direct cost savings to the health sector. Inputs to the model itself were updated from the default loaded data where new and reliable figures were available. Median age of use for IUDs and Implants was updated from the 2014 GDHS data. Unmet need was updated using more recent Track20 data. ImpactNow uses the USAID Couple Years of Protection conversion factors (Stover et al., 2000).

\section{Methodology for modeling changes to modern CPR}

We used two sources of data for estimating the impact on mCPR of our two scenarios involving interventions. The Ghana NHIA pilot program allowed us to estimate the impact on mCPR in pilot districts from solely the cost reimbursement (removal of out-of-pocket FP fees) intervention, and where a combination of removal of fees with LARC training and demand generation activities is undertaken. The Population Council - Ghana team provided data by district containing treatment and control identification and sociodemographic information that included populations, rural populations, total fertility rates, number of women of reproductive age, and number of health facilities including hospitals, health centers, and CHPS. These data were supplemented with data from the District Health Information Management System (Dhims), which provided monthly information on the number of continuing users and new adopters by contraceptive method at the district level. The method-level new adopters were aggregated into a single new adopter dependent variable, representing an additional user of contraception to factor into mCPR, to allow for analysis through a single model. The NHIS pilot removed all out-of-pocket costs for all modern clinical FP methods (IUDs, implants, injectables, tubal ligation, and vasectomy). This informed the decision to include only these services into the new adopter variable.

3 https://www.usaid.gov/global-health/health-areas/family-planning/couple-years-protection-cyp 
Our model for estimating the impacts of the scenarios above on mCPR took the form:

$$
\log Y_{t}=\beta_{0}+\beta_{1} T+\sum_{i=0, j=0, k=0}^{1} \beta_{i, j, k} X_{i, j, k, t}+\ldots+\beta_{m} X_{m}+e, \text { where }
$$

i. $\quad$ T: month in which observations were taken;

ii. $\quad X_{i, j, k, t}$ : a set of dummy variables indicating selection of a district into intervention $i$ : claims reimbursement, $j$ : demand generation, or $k$ : LARC training, during month $t$;

iii. $\quad \beta_{i, j, k}$ : coefficient of estimated impact on new acceptors, where $i, j, k=1$ indicates implemented intervention $i$ : claims reimbursement, $j$ : demand generation, or $k$ : LARC training,

iv. $\log Y_{t}: \log$ transformation of new acceptors during month $t$;

v. $X_{m}$ : a set of independent or covariate variables.

Each intervention arm was implemented in separate months and we controlled for this by using binary indicators for months where each intervention was active. These dummy variables were included as interaction terms in the model to better estimate the impact of each intervention and when more than one is implemented concurrently. In this model, the coefficients within $\beta_{i, j, k}$ represent the geometric means of the iterations of the possible interventions, which can be exponentiated to give the percentage impact on new adopters from the interventions.

\section{Results for modeling changes to $\mathrm{mCPR}$}

The results of the regression model (see Appendix A) show a significant and positive impact on uptake only when all three interventions are concurrently active. There is insufficient evidence to show a significant impact of the claims reimbursable program alone.

Transforming the log coefficient of the impact of all three programs, we find that new adopters increases by $21.8 \%$. When we constrain this to only women with active coverage under the NHIS (45.9\%) as discussed earlier in this report, we can estimate the increase in mCPR from the NHIA implementing all three programs to be $9.9 \%$, or $2.0 \%$ annually over the five years of the model.

Estimating the increase in $\mathrm{mCPR}$ from provision of claims reimbursable $\mathrm{FP}$ services is less straightforward as the model produced insufficient evidence to show a significant impact from the program. As discussed previously in this report, cost as a barrier is reported by few Ghanaian women and this result is in support of that finding. However, policymakers may support the hypothesis that barriers to participation would be mitigated upon scale up of the program to the entirety of the country and emergence of normalization among participants. If these better-case scenarios are experienced, we provide that a reasonable estimate of an impact would be the upper bound of the 95 percent confidence interval. The exponent of the coefficient in our model suggests an increase in mCPR from claims reimbursable FP services of $9.2 \%$. Constraining again by only women with active coverage under NHIS, we estimate the increase in mCPR from the NHIS implementing this program to be $4.2 \%$, or $0.8 \%$ annually. 


\section{Method Mix used for cost modeling}

The ImpactNow tool utilizes changes from baseline method mix as a component of health impacts. We estimated the 2025 method mix for our modeled scenarios.

For our basic out-of-pocket cost removal of FP services scenario, we estimate a change in method mix by 2025 as equivalent to the method mix in December 2019 (the final month of the Dhims data) in pilot districts where only the cost removal intervention was implemented. For the multiple intervention and maximum attainable mCPR scenarios, the change in method mix is TABLE 5. Method mix projections

\begin{tabular}{lcc}
\hline Method & $2020(\%)$ & $2025(\%)$ \\
\hline IUDs & 2.0 & 2.1 \\
Implants & 21.5 & 23.7 \\
Injectables & 24.3 & 21.8 \\
Female Sterilizations & 4.9 & 5.0 \\
Male Sterilizations & 0.0 & 0.0 \\
\hline
\end{tabular}
estimated as equivalent to the method mix in all treatment districts in the pilot in the final month of the Dhims data. For these scenarios, the 2017 GMHS method mix was used as a baseline as it is the closest to the 2020 baseline year in these scenarios.

Completeness of Dhims data is limited for non-clinical methods (e.g., condoms, oral contraceptives, emergency contraception) and methods that do not require any health visit (LAM, cycle beads). Therefore, the final estimation for each method mix was determined by looking at changes in method use over time and scaled to form a complete method mix with the non-clinical and traditional methods. For our modeled scenarios, the 2025 projection was estimated as a change in the composition of the number of clinical method users within the pilot districts from the four months prior to the implementation of claims reimbursement (January 2018 to April 2018) to the last four months of available data (September 2019 to December 2019). Using this methodology, 2020 and projected 2025 method mixes were calculated with the outcomes given TABLE 5.

\section{Projections of Maternal Mortality Rate}

ImpactNow uses projections of MMR in its estimation of health impacts. We project MMR in Ghana for our scenarios through a simple model that relies on historic data. The MMR in Ghana has experienced a downward trend that has been nearly perfectly linear from 2005 to 2017, which is the last year data is available. We see that for 2020, the MMR is predicted to be $297.2 / 100,000$ births and in 2025 it is projected to be $275.5 / 100,000$ live births. 
FIGURE 1. Maternal mortality rate in Ghana (2005 - 2017)

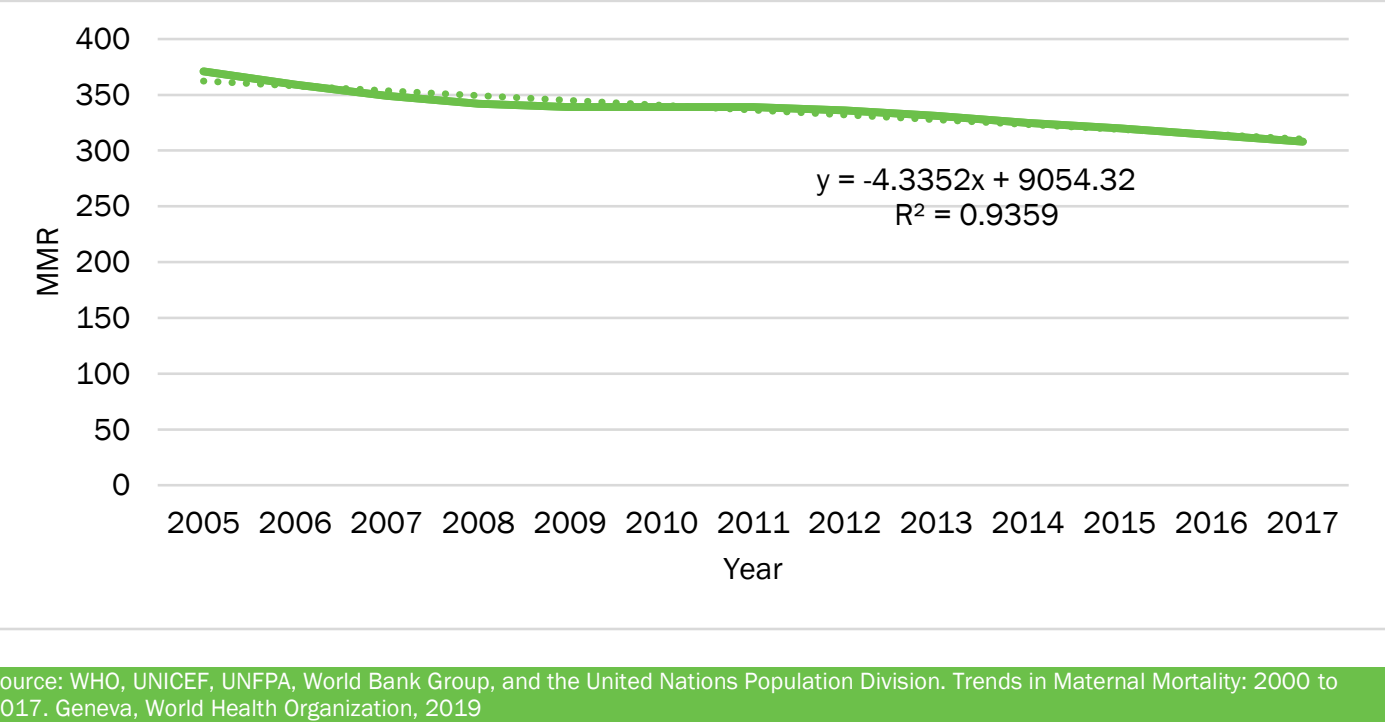

\section{Cost Calculations}

ImpactNow also utilizes the costs of FP methods in its estimations of two of our outcomes of interest: total FP costs and direct costs saved to the healthcare system. We use the default values for the relevant inputs. These include the average annual direct cost per user per method (from Darroch et al., 2017), the effectiveness of contraceptives (from Arévalo et al., 2002; Bradley et al., 2019; Trussell, 2011), the percentage of births requiring attention (Darroch, 2018; Health Policy Project et al., 2014) ${ }^{4}$, the percentage of those births that are able to receive attention (Darroch, 2018; Ghana Statistical Service (GSS) et al., 2015; Health Policy Project et al., 2014; WHO \& UNICEF, 2018), and the associated

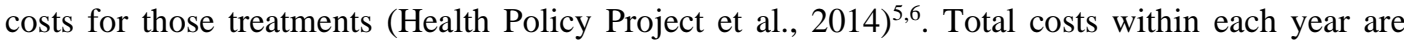
calculated using estimates of the total number of users per contraceptive method (using the population of women 15-49, method mix, and CPR within the selected country for that year) and the annual cost per method.

Total healthcare costs averted are the combination of the costs of unintended pregnancies averted and the costs of live births averted. The cost of unintended pregnancies averted is calculated from the number of pregnancies averted by each method (estimated as the number of users of each contraceptive method), the pregnancy rate, and the rate of failure for each method. Long term methods have a fertility discount rate applied to the pregnancy rate. The cost of live births averted is calculated from the number of lives births per unintended pregnancy, the number of unintended pregnancies averted, the percentage of births requiring attention for a range of treatments e.g. delivery care, postpartum care, mastitis, vaccination, etc., the number of these that are able to receive treatment, and the associated costs for the treatments.

\footnotetext{
${ }^{4}$ From Darroch 2018 and Health Policy Project assumptions

${ }^{5}$ Also used UNFPA's PMNCH Costing tools. WHO; World Health Organization.

http://www.who.int/pmnch/knowledge/publications/costing_tools/en/

6 From Health Policy Project calculations on UNICEF vaccine price data
} 


\section{Cost-Effectiveness}

The cost-effectiveness for each modeled scenario can be estimated by comparing the cost per Disability-Adjusted Life Years (DALYs) averted (due to women using contraception) to average per capita income in Ghana. Interventions where this ratio is less than one are considered very costeffective, whereas those that cost less than three times the average per capita income per DALY averted are still considered cost-effective and those that exceed this level are considered not costeffective (Hutubessy et al., 2003) ${ }^{7}$.

DALYs averted are estimated within ImpactNow by combining total maternal DALYs averted (itself a combination of the number of years of life lost and the years lost due to disability) and preceding birth interval infant DALYs averted.

We obtain average per capita income from the World Bank's measure of Gross National Income (GNI) per capita expressed in current international dollars converted by purchasing power parity (PPP) conversion factor. The most recent available figure for this is from 2018, where GNI per capita, PPP was 5,220.0.

\footnotetext{
${ }^{7}$ Note that this measure of cost-effectiveness is indicative only and if used for funding decisions it should be used in conjunction with other factors such as the local context, equitable access to services, and availability of resources.
} 


\section{Results}

Updated figures and estimates were input into ImpactNow to obtain estimates on health and cost impacts of our four scenarios, which are detailed in the following section. Of most interest to policy makers and program implementers is the impact of the two intervention scenarios, which can be compared against the non-intervention scenario (our 'baseline') and the maximum mCPR scenario. As expected, outcomes across our scenarios are most beneficial where mCPR is projected to increase most.

\section{Impact of Modeled Scenarios}

\section{Unintended pregnancies averted}

In 2025, annual unintended pregnancies averted in the non-intervention scenario totals an estimated 789,000 , with a cumulative total of 3,560,561 in the period from 2021 to 2025 . When only the removal of FP service costs program is implemented, and mCPR increases by $0.32 \%$ annually, an estimated additional 126,000 unintended pregnancies would be averted in 2025, and an additional 369,876 cumulative unintended pregnancies would be averted between 2021 and 2025. The 2025 figure increases by an additional 301,800 for our scenario where demand generation and LARC training are also implemented, where mCPR increases $0.558 \%$ annually. Cumulative unintended pregnancies averted between 2021 and 2025 total 4,441,218, or 880,657 above the non-intervention scenario. The final maximum mCPR increase scenario, where mCPR increases $0.92 \%$ annually, results in an additional 569,000 unintended pregnancies averted above the non-intervention scenario in 2025, and $1,660,039$ unintended pregnancies averted cumulatively.

FIGURE 2. Number of unintended pregnancies averted by intervention scenario, 2021-2025

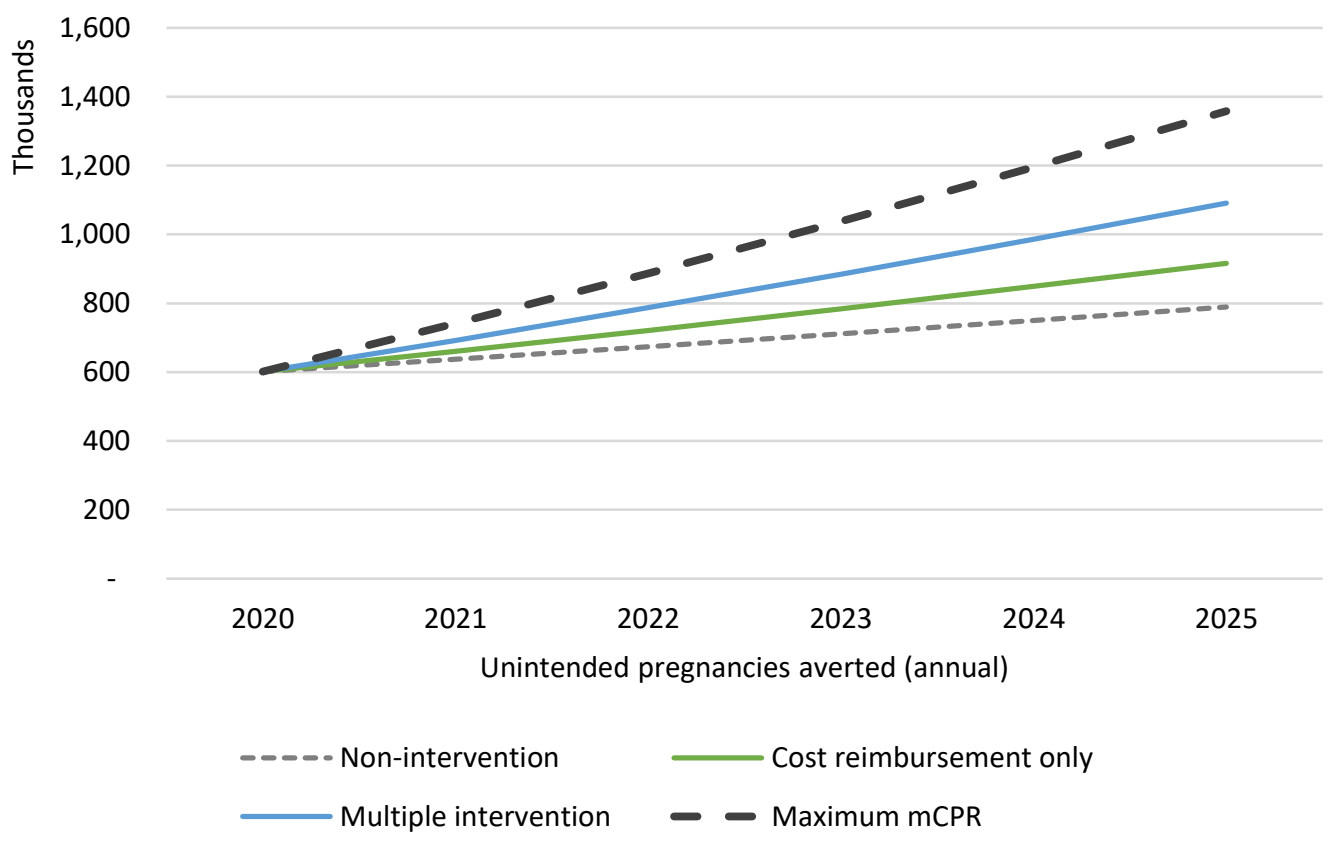


TABLE 6. Unintended pregnancies averted by year, 2021-2025

\begin{tabular}{|c|c|c|c|c|c|c|}
\hline & 2021 & 2022 & 2023 & 2024 & 2025 & Cumulative \\
\hline $\begin{array}{l}\text { Non-intervention } \\
(0.8 \% \text { annual mCPR } \\
\text { increase) }\end{array}$ & 637,007 & 673,566 & 711,118 & 749,664 & 789,206 & $3,560,561$ \\
\hline $\begin{array}{l}\text { Cost reimbursement } \\
\text { only } \\
\text { (1.60\% annual mCPR } \\
\text { increase) }\end{array}$ & 660,281 & 721,152 & 784,053 & 848,989 & 915,962 & $3,930,437$ \\
\hline $\begin{array}{l}\text { Multiple intervention } \\
\text { ( } 2.79 \% \text { annual mCPR } \\
\text { increase) }\end{array}$ & 692,422 & 786,866 & 884,773 & 986,151 & $1,091,006$ & $4,441,218$ \\
\hline $\begin{array}{l}\text { Maximum mCPR } \\
\text { (4.60\% annual mCPR } \\
\text { increase) }\end{array}$ & 741,466 & 887,136 & $1,038,458$ & $1,195,442$ & $1,358,099$ & $5,220,600$ \\
\hline
\end{tabular}

\section{Maternal and infant deaths averted}

In the non-intervention scenario total infant and maternal deaths averted in 2025 is estimated at 10,685, with 48,405 deaths averted across 2021 through 2025. Implementing solely FP service cost removal increases this estimate by 1,800 deaths averted in 2025 and 5,000 deaths averted across 2021 through 2025. This increases to an above baseline scenario of 4,100 deaths averted in 2025 and 11,900 cumulative deaths averted from 2021 to 2025 in the multiple intervention scenario. The maximum mCPR increase scenario results in an estimated 7,800 deaths averted in 2025 and 22,500 cumulative deaths averted above the non-intervention scenario.

FIGURE 3. Maternal and infant deaths averted by intervention scenario, 2021-2025

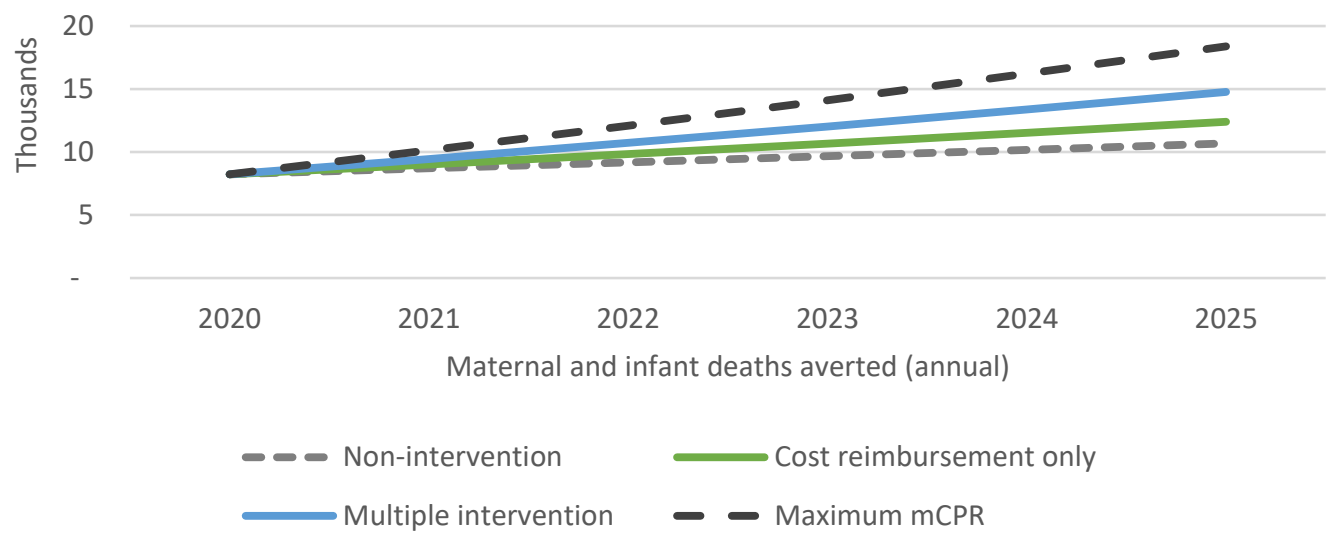


TABLE 7. Maternal deaths averted by year, 2021-2025

\begin{tabular}{|c|c|c|c|c|c|c|}
\hline & 2021 & 2022 & 2023 & 2024 & 2025 & Cumulative \\
\hline $\begin{array}{l}\text { Non-intervention } \\
\text { (0.8\% annual mCPR } \\
\text { increase) }\end{array}$ & 1,269 & 1,322 & 1,375 & 1,428 & 1,480 & 6,874 \\
\hline $\begin{array}{l}\text { Cost reimbursement only } \\
\text { (1.60\% annual mCPR } \\
\text { increase) }\end{array}$ & 1,316 & 1,416 & 1,516 & 1,617 & 1,717 & 7,582 \\
\hline $\begin{array}{l}\text { Multiple intervention } \\
\text { ( } 2.79 \% \text { annual mCPR } \\
\text { increase) }\end{array}$ & 1,380 & 1,545 & 1,711 & 1,878 & 2,045 & 8,559 \\
\hline $\begin{array}{l}\text { Maximum mCPR } \\
\text { (4.60\% annual mCPR } \\
\text { increase) }\end{array}$ & 1,478 & 1,742 & 2,008 & 2,277 & 2,546 & 10,050 \\
\hline
\end{tabular}

TABLE 8. Infant deaths averted by year, 2021-2025

\begin{tabular}{|c|c|c|c|c|c|c|}
\hline $\mathrm{C}_{1}$ & 2021 & 2022 & 2023 & 2024 & 2025 & Cumulative \\
\hline $\begin{array}{l}\text { Non-intervention } \\
\text { (0.8\% annual mCPR } \\
\text { increase) }\end{array}$ & 7,430 & 7,857 & 8,295 & 8,744 & 9,205 & 41,531 \\
\hline $\begin{array}{l}\text { Cost reimbursement only } \\
\text { (1.60\% annual mCPR } \\
\text { increase) }\end{array}$ & 7,702 & 8,412 & 9,145 & 9,903 & 10,684 & 45,845 \\
\hline $\begin{array}{l}\text { Multiple intervention } \\
\text { ( } 2.79 \% \text { annual mCPR } \\
\text { increase) }\end{array}$ & 8,077 & 9,178 & 10,320 & 11,503 & 12,726 & 51,803 \\
\hline $\begin{array}{l}\text { Maximum mCPR } \\
(4.60 \% \text { annual mCPR } \\
\text { increase) }\end{array}$ & 8,649 & 10,348 & 12,113 & 13,944 & 15,841 & 60,894 \\
\hline
\end{tabular}

\section{Disability-Adjusted Life Years averted}

Under the non-intervention scenario, our model estimates a total of 863,000 DALYs averted in 2025 and a cumulative 3,900,984 DALYs averted from 2021 through 2025. Implementing the removal of FP service costs would avert an additional 138,000 DALYS in 2025, a 16\% increase, and a cumulative 405,500 DALYs averted from 2021 through 2025, a 10\% increase. Including demand generation and LARC training implementation would increase the number of averted DALYs in 2025 to 330,000 above the baseline figure, representing a 38\% increase. Cumulative DALYs averted from 2021 through 2025 above the non-intervention scenario totals 965,456, a 24\% increase. The maximum mCPR increase scenario would provide an estimated 622,000 DALYs averted beyond the baseline figure in 2025, which is a $72 \%$ increase. From 2021 to 2025 cumulatively, this figure reaches $1,819,884$ DALYs averted, a $47 \%$ increase. 
FIGURE 4. Number of disability-adjusted life years averted by intervention scenario, 2021-2025

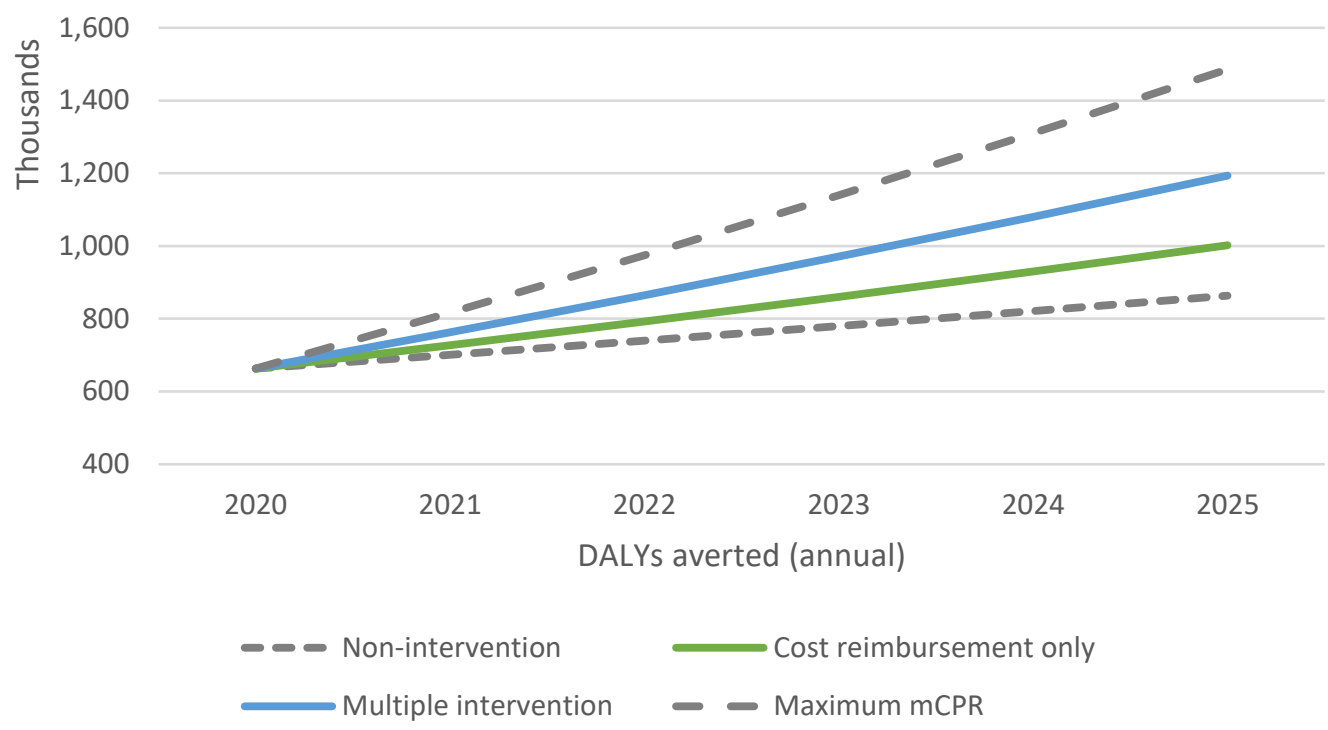

TABLE 9. Disability Adjusted Life Years averted by year, 2021-2025

\begin{tabular}{lcccccc}
\hline & $\mathbf{2 0 2 1}$ & $\mathbf{2 0 2 2}$ & $\mathbf{2 0 2 3}$ & $\mathbf{2 0 2 4}$ & $\mathbf{2 0 2 5}$ & Cumulative \\
\hline $\begin{array}{l}\text { Non-intervention } \\
\text { (0.8\% annual mCPR }\end{array}$ & 701,261 & 740,365 & 780,435 & 821,466 & 863,457 & $3,906,984$ \\
increase) & & & & & & \\
$\begin{array}{l}\text { Cost reimbursement } \\
\text { only }(1.60 \% \text { annual } \\
\text { mCPR increase) }\end{array}$ & 726,883 & 792,670 & 860,479 & 930,304 & $1,002,138$ & $4,312,475$ \\
$\begin{array}{l}\text { Multiple intervention } \\
(2.79 \% \text { annual mCPR }\end{array}$ & 762,267 & 864,901 & 971,017 & $1,080,604$ & $1,193,651$ & $4,872,440$ \\
$\begin{array}{l}\text { increase) } \\
\text { Maximum mCPR } \\
\text { (4.60\% annual mCPR } \\
\text { increase) }\end{array}$ & 816,257 & 975,115 & $1,139,683$ & $1,309,941$ & $1,485,872$ & $5,726,868$ \\
\end{tabular}

\section{Healthcare costs averted}

The total value of the cumulative maternal and infant healthcare costs averted in 2025 is estimated for the non-intervention scenario at $\$ 27.00$ million (GHS 156.60 million $^{8}$ ) and for the cumulative costs averted from 2021 to 2025 at $\$ 121.80$ million (GHS 706.44 million). Removal of FP service costs increases this in 2025 by approximately $\$ 4.33$ million (GHS 27.03 million), or $\$ 12.65$ million (GHS 73.37 million) cumulatively. Including demand generation and LARCs training averts $\$ 10.32$ million (GHS 59.86 million) in 2025, or a cumulative \$30.12 million (GHS 174.70 million) beyond the nonintervention scenario, and the maximum mCPR increase scenario results in $\$ 19.46$ million (GHS 112.87 million) or a cumulative $\$ 56.78$ million (GHS 329.32 million) in healthcare costs averted above the non-intervention scenario. In all scenarios, ratio of benefit to cost persists at 2.35 .

8 Using the USD/GHS exchange rate on September 4, 2020 of 1.00/5.80

17 | Research Report 
FIGURE 5. Healthcare costs averted by intervention scenario, 2021-2025

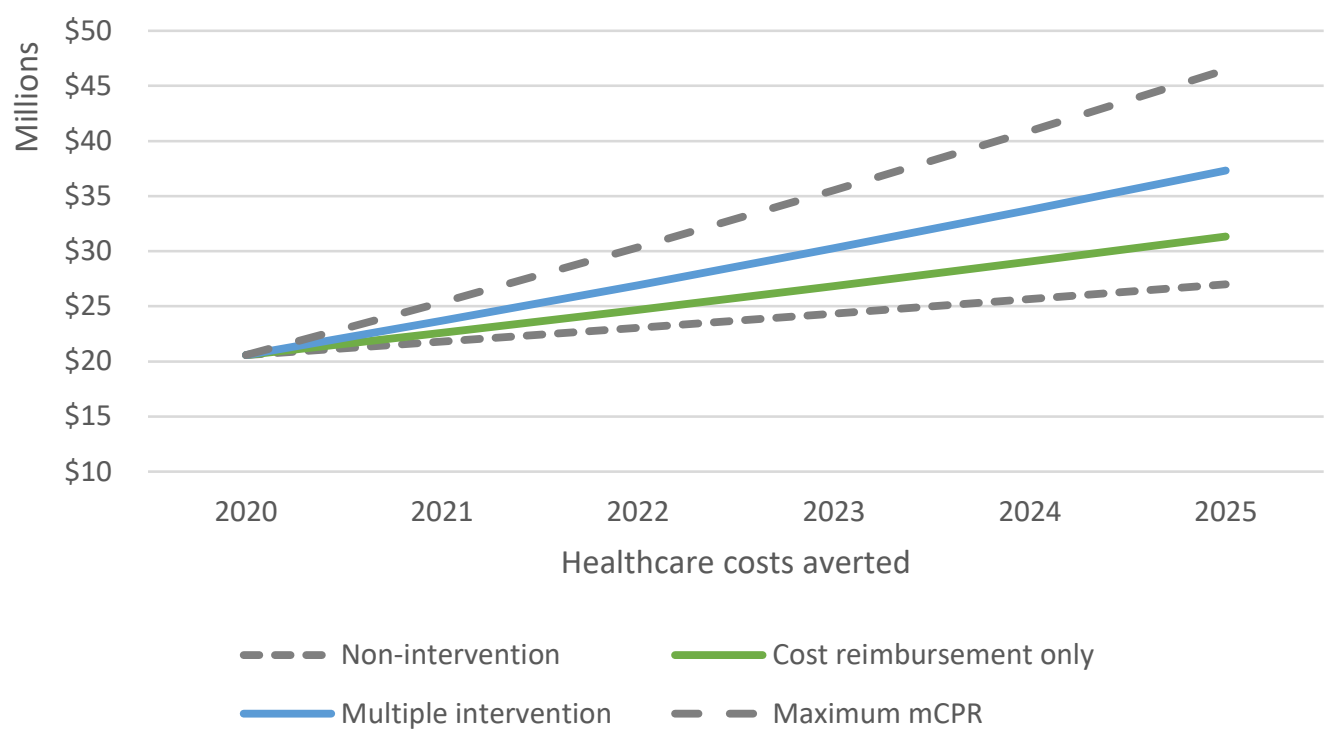

TABLE 10. Healthcare costs averted by year, 2021-2025

\begin{tabular}{|c|c|c|c|c|c|c|}
\hline 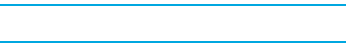 & 2021 & 2022 & 2023 & 2024 & 2025 & Cumulative \\
\hline $\begin{array}{l}\text { Non-intervention } \\
\text { (0.8\% annual mCPR } \\
\text { increase) }\end{array}$ & $\$ 21.79 m$ & $\$ 23.04 \mathrm{~m}$ & $\$ 24.30 \mathrm{~m}$ & $\$ 25.64 m$ & $\$ 27.00 \mathrm{~m}$ & $\$ 121.80 \mathrm{~m}$ \\
\hline $\begin{array}{l}\text { Cost reimbursement only } \\
\text { (1.60\% annual mCPR } \\
\text { increase) }\end{array}$ & $\$ 22.59 m$ & $\$ 24.67 \mathrm{~m}$ & $\$ 26.82 \mathrm{~m}$ & $\$ 29.04 m$ & $\$ 31.33 \mathrm{~m}$ & $\$ 134.45 \mathrm{~m}$ \\
\hline $\begin{array}{l}\text { Multiple intervention } \\
\text { ( } 2.79 \% \text { annual mCPR } \\
\text { increase) }\end{array}$ & $\$ 23.68 \mathrm{~m}$ & $\$ 26.92 \mathrm{~m}$ & $\$ 30.26 \mathrm{~m}$ & $\$ 33.73 \mathrm{~m}$ & $\$ 37.32 \mathrm{~m}$ & $\$ 151.92 m$ \\
\hline $\begin{array}{l}\text { Maximum mCPR } \\
\text { (4.60\% annual mCPR } \\
\text { increase) }\end{array}$ & $\$ 25.36 \mathrm{~m}$ & $\$ 30.35 \mathrm{~m}$ & $\$ 35.52 m$ & $\$ 40.90 m$ & $\$ 46.46 \mathrm{~m}$ & $\$ 178.58 m$ \\
\hline
\end{tabular}

\section{Cost Effectiveness}

ImpactNow's estimations of total FP costs and DALYs averted scale linearly and so the cost per DALY averted in all scenarios are an equivalent \$13.31 per DALY averted in 2025. With an average per capita income of $\$ 5,220.00$, the cost of delivering FP services resulting from the two interventionbased scenarios presented are both cost-effective.

\section{FP interventions in Ghana (current and planned) that may also impact on modern FP uptake}

While this report considers the impact of the removal of out-of-pocket fees for FP services, increased access to LARCs, and demand generation programs, the Government of Ghana also identified several other priorities in their 2012 FP2020 commitment that we do not consider in the analysis but should be highlighted. These include task sharing to increase method choice and access to long acting or permanent methods; increasing demand through male involvement; improving quality of services; increasing access to adolescents and youth; and increasing method choice and access to postpartum 
and post-abortion sexual and reproductive health care (London Summit on Family Planning, 2013 ${ }^{9}$ ). In 2017, the Government of Ghana refined their priorities to increase their progress towards achieving their FP2020 goals, including: increased government spending on FP procurements to ensure service sustainability and improve commodity security; increasing FP access in peri-urban and rural areas; increasing access to information and services for adolescents; and rolling out Social and Behaviour Change Communication activities focused on rights-based FP (FP2020, 2018).

Other activities that are not specific to the government but may have an impact on FP uptake include a new focus from USAID on Northern Ghana, introduction of new methods, such as Sayana Press, and social marketing by service delivery organizations (correspondence with The Population Council Ghana).

Finally, Results for Development has piloted 'Preferred Primary Care Provider Networks' in Ghana to explore whether, by acting as a network, providers are able to: improve quality of and access to healthcare through sharing of resources, referrals and coaching and mentoring; improve efficiency of service delivery and financing; and better leverage available funding opportunities. Early results suggest that a network model can improve efficiency of submitting and receiving claims, and increase the number of referrals.

This varied range of interventions and programs all aimed at improving the quality of and access to FP services have not been built into our mCPR models, suggesting that we may be underestimating likely mCPR increase over the next five years.

\section{Assumptions and Limitations}

Our modeling exercise had a number of limitations. First, as with all modeling, we are only able to make estimations of likely uptake, impact and cost. It is impossible to predict with great certainty how the interventions will affect mCPR. Similarly, we are limited by the availability, quality and completeness of the data on which our models rely.

Second, it is important to note that the intervention design can vary, and that even small variations can have an effect on FP uptake, so while our models are based on data from results of the pilot interventions, they may differ in crucial ways from the final way in which out-of-pocket cost removal and accompanying interventions are conducted in Ghana. Our data will only reflect potential increase in uptake due to the interventions done as per the pilot and programs we included in our analysis. Equally, the pilot took place in nine districts, while our model estimates national level mCPR change and health outcomes. Although we have adjusted our estimates for difference between regions, it is possible that the pilot districts may differ from other areas of Ghana in unknown ways and that mCPR change might be higher or lower in other parts of the country. Similarly, while we controlled for interactions where they could be empirically determined from the pilot data, it is difficult to estimate how different interventions will interact.

Third, the estimate of each intervention's impacts implicitly assumes that they were implemented completely and uniformly within all months where the associated indicator variable was enabled. For instance, benefits from training may be present in the interim months, and skill loss from lack of practice may exist during the initial program onset period. We consider it more likely that each impact estimate is conservative, where more program periods run below normal than above. As such, our outcome indicators would also be conservative.

\footnotetext{
${ }^{9}$ London Summit on Family Planning. Summaries of Commitments. 2 December 2013. UKAID
} 
Fourth, we acknowledge that inherent in this analysis is the possibility that there is no significant impact from the out-of-pocket cost removal program and understanding the health impacts predicated on this mCPR estimate should include this possibility.

Fifth, not all planned or ongoing interventions have been included in the estimation of mCPR increase. Interventions were excluded based on the following criteria:

1. there are not enough details about what the intervention entails

2. it is not clear if/when the intervention will start

3. it is not possible to estimate the impact of the intervention on FP uptake

4. the intervention is outside the scope of what we would consider an FP intervention.

Interventions not included in the analysis for the above reasons are included descriptively above.

Sixth, measurements and projections of mCPR in Ghana have fluctuated from 2008 to present. The 2015 modeling exercise discussed in Appendix B used a CPR of 37.3 percent for their 2014 baseline based on the average annual change from 1993 through 2011. The 2014 GDHS was released after their analysis was conducted and found that the CPR had fallen to 23 percent. The non-intervention scenario used as a lower bound in our analysis utilizes a mCPR that projects an average annual change from the 10 years previous to 2020. A significant fluctuation in expected mCPR would disrupt our findings. However, smaller deviations from our projected mCPR trend would only marginally affect our impact estimations and policymakers should consider the drivers of those deviations in how any impact would be altered.

Seventh, the COVID-19 pandemic that began in late 2019 has not spared Ghana and has resulted in 44,713 infections and 280 deaths as of September 4, 2020. The impact on contraceptive use among Ghanaian women is not yet known but must be considered, especially in our non-intervention scenario that serves as both a lower bound of mCPR expectations and as a baseline for which to compare the intervention scenarios. While the likelihood of a negative impact to $\mathrm{mCPR}$ in the short run is high, a return to pre-COVID-19 usage patterns by 2025 is also likely. Interpretation of the health and cost outcomes of our model should consider this short-term impact.

Finally, our measure of cost-effectiveness is based on generic total FP cost estimates from ImpactNow and is based on global cost data and is not country or program-specific. NHIS reimbursement, as well as other factors such as the number of training sessions and development of information education and communication (IEC) materials, would affect the actual program costs. 


\section{Conclusion}

The impact of Ghana's NHIA and GHS implementing FP services cost reimbursement, LARC training, and demand generation program is significant and positive across measurements of lives saved and healthcare costs averted. From 2021 through 2025, the cost reimbursement program alone would result in an additional estimated 48,405 infant and maternal lives saved and 369,876 unintended pregnancies averted beyond a scenario where no other interventions are implemented. In addition, FP service cost reimbursement would save \$12.65 million (GHS 73.37 million) cumulatively in healthcare costs from 2021 to 2025 above the non-intervention scenario, which is greater than the estimated \$7.5 million (GHS 43.5 million) in additional costs to reimburse for FP services over that time. This 1.69 benefit-cost ratio shows that the cost savings of implementing these initiatives would outweigh the costs of the initiatives themselves. Using the program cost estimates from ImpactNow shows that this program is highly cost-effective, based on international measures of cost-effectiveness. Expanding the initiative to include demand generation activities and LARC training across the country would increase the number of infant and maternal lives saved and unintended pregnancies averted from 2021 through 2025 by an additional $24.6 \%$. These two programs would add $\$ 12.9$ million (GHS 74.8 million) in total FP costs from 2021 through 2025 but would avert \$30.1 million (GHS 174.7 million) in other healthcare costs.

Avenir Health's estimation for the maximum possible mCPR in Ghana is $45 \%$ by 2025 . Implementing FP service cost reimbursement would advance mCPR from our baseline projection of $26.2 \%$ to $30.4 \%$ in 2025, making up one-fifth of this gap. The addition of demand generation activities and LARC training advances mCPR to an estimated $36.2 \%$, just over half of that gap. These programs will bring access to FP to women covered by the NHIS, and efforts to expand coverage would only further diminish the gap.

The results from this analysis show that removal of financial barriers to FP will have a potentially small positive effect on FP uptake, mCPR, and long-term health outcomes, and a much greater impact will be seen if additional interventions are also implemented. Training providers on LARCs delivery and demand generation activities were both found to substantially increase the impact of removing of financial barriers on mCPR. Inclusion of FP in the NHIS benefits package focuses only on the financial barriers to FP access, while LARC training and demand generation address additional barriers such as availability of and awareness of FP. It is crucial that any intervention reaches women who are not currently using FP since it is only by reaching those women that any impact on mCPR will be seen. 


\section{References}

Achana, F. S., Bawah, A. A., Jackson, E. F., Welaga, P., Awine, T., Asuo-Mante, E., Oduro, A., Awoonor-Williams, J. K., \& Phillips, J. F. (2015). Spatial and socio-demographic determinants of contraceptive use in the Upper East region of Ghana. Reproductive Health, 12(1), 29. https://doi.org/10.1186/s12978-015-0017-8

Ankomah, A., Kuffour, E. O., Fuseini, K., Bellows, B., RamaRao, S., Haruna, R., Mensah-Annan, R. A., Nsiah-Boateng, E., \& Aboagye, P. K. (2020). Evaluating the Inclusion of Family Planning Within the National Health Insurance (NHI) Benefits Package in Ghana: Quantitative Pre-Study Inception Report (Revised). Population Council.

Arévalo, M., Jennings, V., \& Sinai, I. (2002). Efficacy of a new method of family planning: The Standard Days Method. Contraception, 65(5), 333-338. https://doi.org/10.1016/s00107824(02)00288-3

Aviisah, P. A., Dery, S., Atsu, B. K., Yawson, A., Alotaibi, R. M., Rezk, H. R., \& Guure, C. (2018). Modern contraceptive use among women of reproductive age in Ghana: Analysis of the 2003-2014 Ghana Demographic and Health Surveys. BMC Women's Health, 18(1), 141. https://doi.org/10.1186/s12905-018-0634-9

Boddam-Whetham, L., \& Duku, S. (2019). Including Family Planning in Ghana's National Health Insurance - from policy to practice. African Health Markets for Equity, Marie Stopes International.

Bradley, S. E. K., Polis, C. B., Bankole, A., \& Croft, T. (2019). Global Contraceptive Failure Rates: Who Is Most at Risk? Studies in Family Planning, 50(1), 3-24. https://doi.org/10.1111/sifp.12085

Chaitkin, M., Schnure, M., Dickerson, D., \& Alkenbrack, S. (2015). How Ghana Can Save Lives and Money: The Benefits of Financing Family Planning through National Health Insurance. Futures Group, Health Policy Project.

Darroch, J. E. (2018). Adding It Up: Investing in Contraception and Maternal and Newborn Health, 2017-Estimation Methodology. Guttmacher Institute.

Darroch, J. E., Sully, E., \& Biddlecom, A. (2017). Adding It Up: Investing in Contraception and Maternal and Newborn Health, 2017-Supplementary Tables. Guttmacher Institute. www.guttmacher.org/fact-sheet/adding-it-up-contraception-mnh-2017

Eldridge, C., \& Staples, H. (2018). A synthesis of recent learnings on the integration of Family Planning in Universal Coverage schemes. Impact for Health Inter-national.

FP2020. (2017). Family Planning 2020 Commitment. Government of Ghana. http://www.familyplanning2020.org/sites/default/files/Ghana_FP2020_Commitment_2017 -0.pdf

FP2020. (2018). Ghana FP2020 Actions for Acceleration (2018-2019). https://www.familyplanning2020.org/sites/default/files/Ghana_2018-

2019_Actions_for_Acceleration_0.pdf

Ghana Statistical Service. (2011). Ghana Multiple Indicator Cluster Survey with an Enhanced Malaria Module and Biomarker, 2011, Final Report. Ghana Statistical Service.

Ghana Statistical Service, Ghana Health Service, \& ICF Macro. (2009). Ghana Demographic and Health Survey 2008. GSS, GHS, and ICF Macro.

Ghana Statistical Service (GSS), Ghana Health Service (GHS), \& ICF. (2018). Ghana Maternal Health Survey 2017. GSS, GHS, and ICF. 
Ghana Statistical Service (GSS), Ghana Health Service (GHS), \& ICF International. (2015). Ghana Demographic and Health Survey 2014. GSS, GHS, and ICF International.

Government of Ghana. (2015). Ghana Family Planning Costed Implementation Plan. Ghana Health Service \& Futures Group, Health Policy Projec.

Health Policy Project, United States Agency for International Development (USAID), \& Marie Stopes International. (2014). ImpactNow Manual, version 2.0, revised 2018. Palladium, Health Policy Project.

Hutubessy, R., Chisholm, D., Edejer, T. T.-T., \& WHO-CHOICE. (2003). Generalized costeffectiveness analysis for national-level priority-setting in the health sector. Cost Effectiveness and Resource Allocation, 1(1), 8. https://doi.org/10.1186/1478-7547-1-8

Mazzilli, C., Appleford, G., \& Boxshall, M. (2016). Page 1of 8MSI's health financing assessments 2012-2015:What did we learn about UHC financing and contraception? Four 'Ps' matter. Marie Stopes International.

Nsiah-Boateng, E., \& Aikins, M. (2018). Trends and characteristics of enrolment in the National Health Insurance Scheme in Ghana: A quantitative analysis of longitudinal data. Global Health Research and Policy, 3(1), 32. https://doi.org/10.1186/s41256-018-0087-6

Performance Monitoring and Accountability 2020 (PMA2020) Project, Kwame Nkrumah, \& University of Science and Technology (KNUST). (2013). Detailed Indicator Report: Ghana 2013. PMA2020.

Stover, J., Bertrand, J. T., \& Shelton, J. D. (2000). Empirically Based Conversion Factors for Calculating Couple-Years of Protection. Evaluation Review, 24(1), 3-46. https://doi.org/10.1177/0193841X0002400101

Track20. (2020). Exploring Opportunities for $m C P R$ Growth in Ghana. Track20. http://www.track20.org/download/pdf/Opportunity\%20Briefs/english/Ghana\%20FP\%20Op portunity\%20Brief.pdf

Trussell, J. (2011). Contraceptive Efficacy. Table 3-2 in Contraceptive Technology (R. A. Hatcher, J. Trussell, A. L. Nelson, W. Cates, D. Kowal, \& M. S. Policar, Eds.; 20th ed.). Ardent Media. WHO, \& UNICEF. (2018). Estimates of national routine immunization coverage, 2017 revision. https://data.unicef.org/resources/dataset/immunization-coverage-antigen-including-trends/

WHO, UNICEF, UNFPA, World Bank Group, \& United Nations Population Divisio. (2019). Trends in maternal mortality 2000 to 2017. World Health Organization. https://www.unfpa.org/sites/default/files/pub-pdf/Maternal_mortality_report.pdf 


\section{Appendix A: Regression table}

TABLE 11. Logistic regression of new acceptors

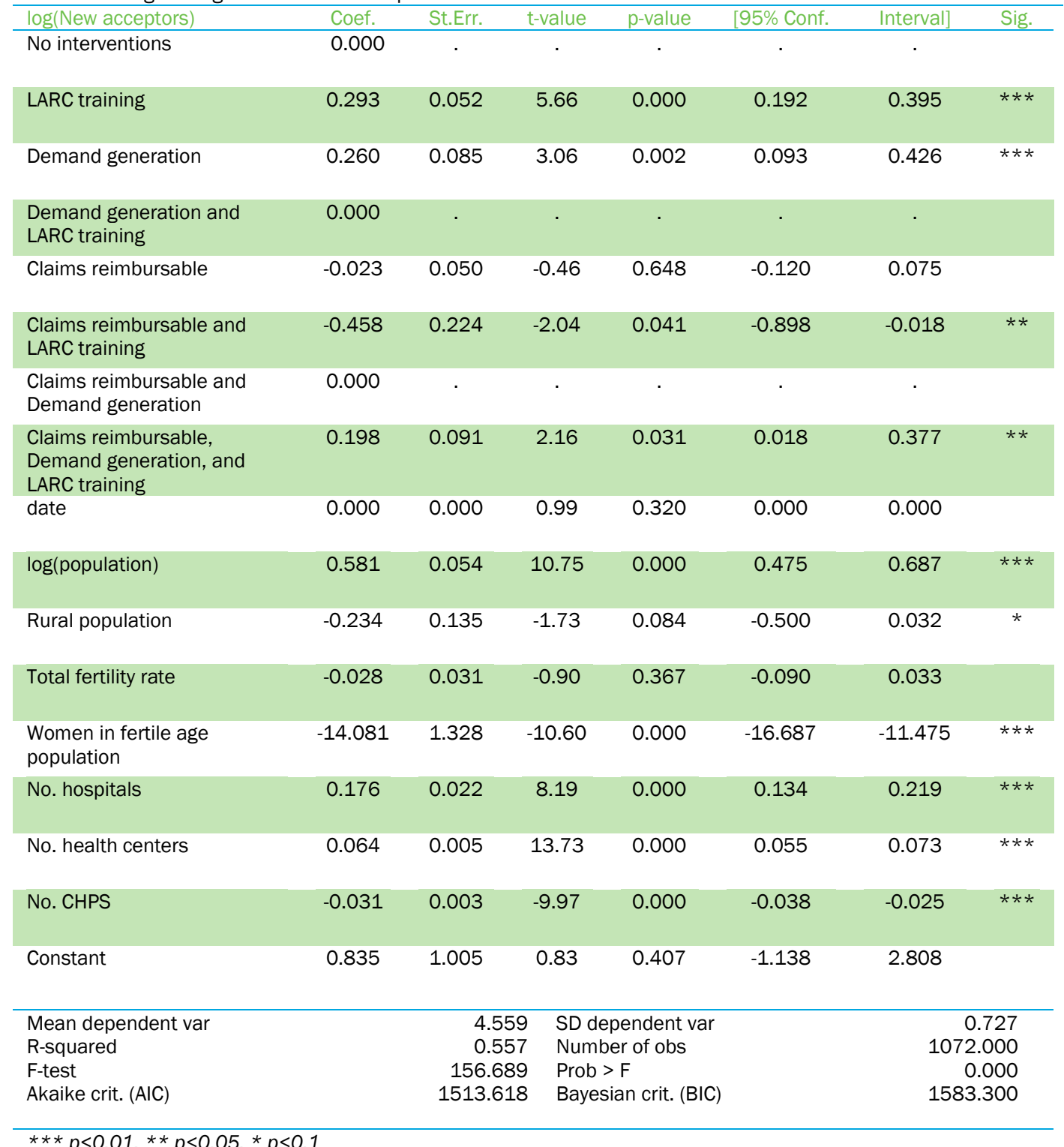

$\star \star \star *<0.01,{ }^{\star *} p<0.05,{ }^{*} p<0.1$ 


\section{Appendix B:}

\section{Review of 2015 report How Ghana Can Save Lives and Money: The Benefits of Financing Family Planning through National Health Insurance}

In 2015, Chaitkin et al. published an analysis that investigated the health and economic benefits at varying levels of investment in FP as projected from 2014 to 2020. Their results showed that all modeled scenarios would be cost-effective investments for reducing maternal and infant mortality and unintended pregnancies as well as reducing overall maternal and infant healthcare related costs. As part of this report, we undertook a validation exercise to compare the results of their scenarios to the state of Ghana at the end of their models' duration (Chaitkin et al., 2015).

In their modeling exercise, Chaitkin et al. estimated CPR increases between 2014 and 2020. They developed four scenarios as follows:

1. A baseline scenario that assumed no new investment or interventions resulting in an average annual increase in CPR of $0.88 \%$ from $37.3 \%$ to $42.6 \%$, continuing along the same trend as seen in Ghana between 1993 and 2011.

2. A conservative scenario that included the removal of financial barriers as the main intervention, resulting in an additional CPR increase of $2.4 \%$ over the baseline between 2014 and 2020, where the CPR in 2020 was estimated at $45.1 \%$.

3. A moderate scenario that included the removal of financial barriers and some additional interventions to increase uptake, and assumes a 5\% CPR increase over the baseline, where the CPR in 2020 was estimated at $47.6 \%$

4. An ambitious scenario that included the removal of financial barriers, additional interventions to increase uptake and demand generation activities and modelled a 10\% CPR increase over the baseline, where the CPR in 2020 was estimated at $52.6 \%$.

Across all four scenarios, differences in the change to method mix resulted in varying impacts to $\mathrm{mCPR}$. Health and cost impacts were estimated in ImpactNow using changes to CPR, and the changes to $\mathrm{mCPR}$ can be found in TABLE 13.

We undertook this validation exercise to enable reflection on the 2015 research in two ways: the first as a methodologic guide in the development of our scenarios and the second to compare their estimated impacts with what was realized in Ghana during that time.

There were a number of key differences between the methods used in the 2015 report and this report. Firstly, thanks to the data collected through the pilot inclusion of FP into the NHIS benefits package in Ghana, we were able to base our calculation of mCPR scenarios on the observed impact on mCPR of various interventions. Secondly, the 2015 report models change in FP uptake between 2014 and 2020, while we modeled change between 2020 and 2025. Thirdly, while the 2015 report used overall $\mathrm{CPR}$, we focused on $\mathrm{mCPR}$, since these are the clinical methods that will be included in the NHIS benefits. Finally, we were able to make use of updated datasets and projections, notably the 2014 GDHS data, which have become available since the release of the 2015 report. Both modelling reports use the ImpactNow tool to model impact of FP services. 


\section{Methods}

To compare the 2015 report's model estimations to updated projections of Ghana in 2020, we followed a similar methodology while changing only those inputs where updated data exists. Method mix in 2020 was obtained from the Ghana's Dhims, mCPR in 2020 has been estimated by the United Nations, Population Division, Fertility and Family Planning Section, and an updated MMR is projected using the same methodology as described earlier in the main body of this report.

\section{Method Mix used for cost modeling}

We estimated a change in method mix from 2015 to 2020 as equivalent to the change in method mix in all districts in Ghana reported within the Dhims data while using the 2014 GDHS method mix as a baseline, as it reports method mix closest to the 2015 baseline year used in this comparison exercise.

\begin{tabular}{|c|c|c|c|}
\hline Completeness of Dhims & TABLE 12. Method mi & & \\
\hline data is limited for non- & Method & 2020 & 2025 \\
\hline condoms. & IUDs & $2.22 \%$ & $2.25 \%$ \\
\hline contraceptives, emergency & Implants & $16.44 \%$ & $17.58 \%$ \\
\hline contraception) and methods & Injectables & $26.67 \%$ & $25.49 \%$ \\
\hline that do not require any & Female Sterilizations & $5.78 \%$ & $6.02 \%$ \\
\hline health visit (LAM, cycle & Male Sterilizations & $0.00 \%$ & $0.00 \%$ \\
\hline
\end{tabular}

beads). Therefore, the final

estimation for each method mix was determined by looking at changes in method use over time and scaled to form a complete method mix with the non-clinical and traditional methods. For this comparison, method mix was estimated in 2015 and in 2020 using the composition of the number of clinical users (IUDs, implants, injectables, tubal ligations, and vasectomies) across all districts in Ghana in 2015 and 2020. The 2014 and 2020 method mixes are given in TABLE 12. 


\section{Results}

When comparing the outcomes of our observed data model with those from the 2015 modeling exercise, we found that the 2015 exercise was overly optimistic in their projections even within their baseline scenario as seen in TABLE 13.

\section{Comparison of 2015 projections with updated data projections}

From 2014 to 2020, the contraceptive prevalence rate for modern methods in Ghana increased from $18.1 \%$ to $22.9 \%{ }^{10}$. This $2020 \mathrm{mCPR}$ figure was significantly below the lowest estimate in the 2015 exercise of $34.7 \%$ used in the "no intervention or new investment" scenario. Health outcomes calculated by ImpactNow for the updated 2020 projection of $22.9 \%$ were as a result well below those estimated in the 2015 scenarios. The 2015 report estimated 747,495 unintended pregnancies averted in 2020 whereas our updated projection estimates this figure at 589,840 , or $79 \%$ of that found in the baseline scenario. Our updated model estimated the number of maternal deaths averted as $65 \%$ of that baseline scenario, and the number of infant deaths averted was only $36 \%$ when being compared. Total FP costs were significantly less with $\$ 9.2$ million representing only $36 \%$ of the estimated costs of $\$ 25.9$ million in the baseline scenario. Costs averted were $42 \%$ of the baseline estimates: $\$ 20.1$ million compared to $\$ 46.5$ million.

TABLE 13. Comparison of 2020 projections vs. 2015 projections

\begin{tabular}{|c|c|c|c|c|c|c|}
\hline & $\begin{array}{c}2014 \\
\text { Baseline }\end{array}$ & $\begin{array}{c}2020 \\
\text { Scenario } \\
1\end{array}$ & $\begin{array}{l}2020 \\
\text { Scenario } \\
2\end{array}$ & $\begin{array}{l}2020 \\
\text { Scenario } \\
3\end{array}$ & $\begin{array}{c}2020 \\
\text { Scenario } \\
4\end{array}$ & $\begin{array}{l}2020 \\
\text { Updated } \\
\text { projections }\end{array}$ \\
\hline CPR & $37.3 \%$ & $42.6 \%$ & $45.1 \%$ & $47.6 \%$ & $52.6 \%$ & $26.7 \%$ \\
\hline mCPR & $24.8 \%$ & $34.7 \%$ & $37.7 \%$ & $40.8 \%$ & $50.5 \%$ & $22.9 \%$ \\
\hline \multicolumn{7}{|c|}{ Health benefits (cumulative) } \\
\hline $\begin{array}{l}\text { Unintended births } \\
\text { averted }\end{array}$ & & 747,495 & 771,767 & 805,993 & 878,029 & 589,840 \\
\hline $\begin{array}{l}\text { Maternal deaths } \\
\text { averted }\end{array}$ & & 1,936 & 1,995 & 2,079 & 2,253 & 1,256 \\
\hline Infant deaths averted & & 19,187 & 19,809 & 20,688 & 22,537 & 6,880 \\
\hline \multicolumn{7}{|c|}{ Total FP costs (cumulative) } \\
\hline Total FP costs & & $\$ 25.9 m$ & $\$ 27.0 \mathrm{~m}$ & $\$ 28.5 \mathrm{~m}$ & $\$ 32.7 \mathrm{~m}$ & $\$ 9.2 \mathrm{~m}$ \\
\hline \multicolumn{7}{|c|}{ Absolute maternal and infant costs averted } \\
\hline $\begin{array}{l}\text { Maternal \& infant costs } \\
\text { averted }\end{array}$ & & $\$ 46.5 \mathrm{~m}$ & $\$ 48.1 \mathrm{~m}$ & $\$ 50.2 \mathrm{~m}$ & $\$ 54.7 \mathrm{~m}$ & $\$ 20.1 \mathrm{~m}$ \\
\hline
\end{tabular}

10 United Nations, Population Division, Fertility and Family Planning Section estimates and projections of family planning indicators 2020. 2015 report utilized Ghana Statistical Service data for mCPR figures. 


\section{Discussion}

The Health Policy Project reported on the impact of financing FP through Ghana's NHIIS benefits package in 2015. Our updated estimations found that the original baseline scenario, in which no FP provision programs were implemented, provided an overestimate of the outcomes of interest in the years that followed. We attribute this primarily to an overestimate of the increase in $\mathrm{mCPR}$, which increased to $26.2 \%$ as opposed to the modeled $34.7 \%$.

Comparing the scenarios with updated mCPR projections for 2020 accomplishes several goals. First, we are able to review their methodology and identify where improvements can be made. Second, the differing impact of inputs into ImpactNow, such as a lower MMR leading to fewer deaths, become apparent. 